\title{
SKIN AND HAIR CHANGES AFTER FORTY
}

Manisha Nijhawan'1, Shifa Yadav², Puneet Aggarwal'3 ${ }^{3}$ Dinesh Mathur ${ }^{4}$

\section{HOW TO CITE THIS ARTICLE:}

Manisha Nijhawan, Shifa Yadav, Puneet Aggarwal, Dinesh Mathur. "Skin and Hair Changes after Forty". Journal of Evolution of Medical and Dental Sciences 2014; Vol. 3, Issue 15, April 14; Page: 4111-4120,

DOI: $10.14260 /$ jemds/2014/2406

INTRODUCTION: Aging is a continuous, dynamic, and an irreversible process. Direct exposure to ultra-violet radiations, skin is particularly prone to early aging, known as photo aging. Skin aging is particularly important because of its visibility and social impact. As women age we will notice changes to our skin and hair during the menopause. Dry, thinning, fragile, less tolerant and sagging skin are common complaints. The main reasons for the change in skin is the loss of estrogen, testosterone and dehydroepiandrosterone (DHEA) etc, ${ }^{1,2,3}$ from the age of 35 onwards up to menopause, the more we have had long-term exposure to the elements, such as sun and wind the more this becomes evident. Estrogen is very involved in the normal function of the skin. It directly affects the function of key cells in the skin, like the fibroblast (produces collagen and elastin), keratinocyte (closely involved in skin protection) and melanocytes (involved in evenness of skin color, etc.). It also helps regulate hair follicle function (hair production) as well as sebaceous gland activity (producing skin oils). After the age of forty most of women enters menopause, during which estrogens levels decreases, which leads to different types of hair and skin changes which has been described in this article.

\section{PATHOPHSIOLOGICAL CHANGES AFTER FORTY:}

There are three stages in menopause:

1. Perimenopause

2. Climacteric

3. Menopause

\section{Age of onset of menopause:}

Usual age 45 to $50 y r s$ average being $47 y$ rs.

Premature menopause - before 40 yrs.

Late menopause - menstruation beyond 52 yrs.

\section{PERIMENOPAUSE:}

- A period of 3years before menopause \& followed by 1 year of amenorrhoea. Associated with mild ovarian hormonal deficiency, Leads to anovulation, menorrhagia.

\section{MENOPAUSE:}

- The time of cessation of ovarian function resulting in permanent amenorrhoea, For confirmation: 12 months

\section{CLIMACTERIC:}

- Phase of waning ovarian activity

- 2-3 yrs. before and 2-5 yrs. after menopause. 
During climacteric, ovarian activity declines.

Initially, ovulation fails, no corpus luteum forms and no progesterone is secreted by the ovary. Later, graffian follicle fails to develop, estrogenic activity decreases and endometrial atrophy leading to amenorrhea.

There is increased secretion of FSH and LH by anterior pituitary. There is 50 times increase in FSH, LH by 3-4 times. Menopausal urine has become an important commercial source of gonadotropins. Later gonadotropin activity of anterior pituitary ceases and fall in FSH level eventually occurs. There is $50 \%$ reduction in androgen production and $66 \%$ reduction in estrogen production. Some estrogen is produced by ovary (oestrone, E1). FSH appears in large concentrations. Low estrogen levels are responsible for ageing of skin and hair follicle. Levels (below 20pg/ml) predispose to osteoporosis and ischemic heart disease.

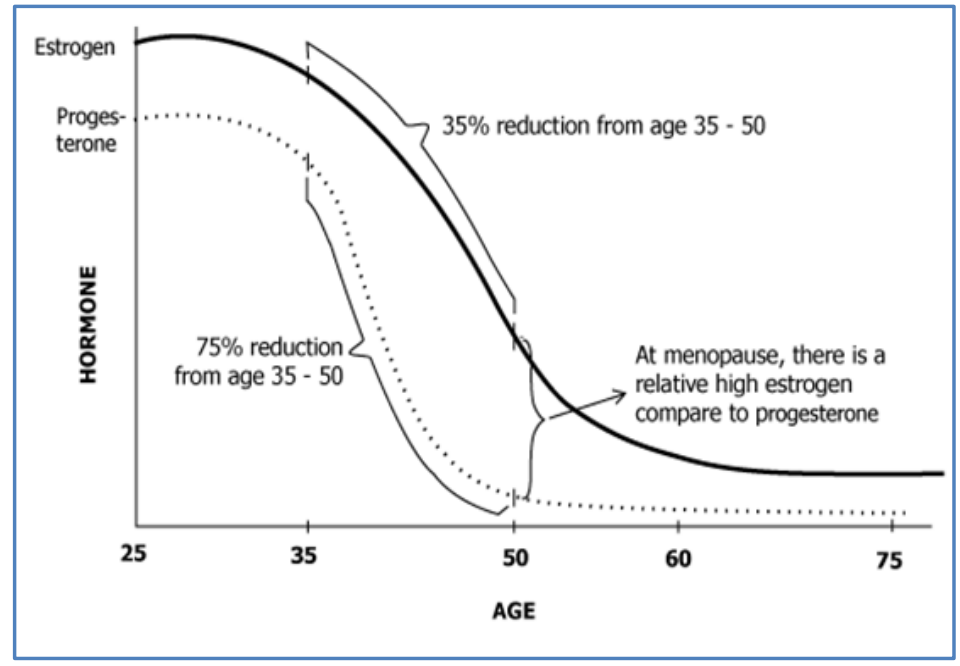

There are two main processes which induces skin aging:

1. Intrinsic aging.

2. Extrinsic aging; includes photo aging and environmental aging.

1. Intrinsic aging: As the cells of the skin age, they become less able to carry on their normal functions. The skin thins as production of collagen and elastin lessens. The hair produced by the skin begins to turn gray. Skin releases superficial dead cells less readily, causing dry and dull-appearing skin. This depends on the genetic make- up of the person.

2. Extrinsic aging: U.V radiation is the major cause of extrinsic ageing also called as photo aging.

\section{a. Photo aging:}

The areas of the body that are exposed to sunlight typically show much more deterioration over time than areas on the same person that aren't exposed to UV rays both UVA (320-400 nm) and UVB (290-320 $\mathrm{nm}$ ), the skin response to the radiations is dependent on the genetic predisposition of an individual.4, 5 . Increased wrinkling on the face compared to the inner arm is generally due to the accumulated damage from sunlight. 
b. Environmental aging: As the outer shield for the body, skin comes into contact with a lot of damaging conditions and materials. Smokers develop what is known as "smokers face" characterized by facial wrinkling and ashy grey appearance of skin ${ }^{6,7}$.

Other agents like Pollutants, Wind, Extreme, temperatures and stress; all of these take their toll as well.

\section{CLASSIFICATION OF AGING:}

Glogau'sphotoagingclassification ${ }^{8}$

\begin{tabular}{|c|c|}
\hline Type & Characteristics \\
\hline No wrinkles & $\begin{array}{l}\text { Typical age } 20-30 \\
\text { Early photo aging with mild pigmentary changes } \\
\text { No keratosis and no minimal wrinkles }\end{array}$ \\
\hline Wrinkles in motion & $\begin{array}{l}\text { Typical age late } 30 \text { to } 40 \\
\text { Early to moderate photo aging } \\
\text { Early sensitive lentigens } \\
\text { Palpable but not visible keratosis } \\
\text { Parallel smile lines beginning to appear } \\
\text { Lateral to mouth }\end{array}$ \\
\hline Wrinkles at rest & $\begin{array}{l}\text { Typical age } 50 \text { or more } \\
\text { Advanced photo aging } \\
\text { Telangiectasia, dyschromia, visible dyskeratosis }\end{array}$ \\
\hline Only wrinkles & $\begin{array}{l}\text { Typical age } 60 \text { or older } \\
\text { Severe photo aging, yellow gray skin } \\
\text { Precancerous lesions with no normal skin }\end{array}$ \\
\hline
\end{tabular}

\section{SKIN CHANGES:}

- Increased loss of collagen -the support structure in the skin, more open pores, facial vein becomes more prominent.

- Decrease in the glycosaminoglycans (GAG's) that provide 'plumpness' to skin which leads to more volume loss.

- Decrease in dermal thickness.

- Decrease in skin elasticity, sagging appears.

- Dry skin, skin becomes rough needs more hydration in winters.

- Fine wrinkling, discolouration.

- Poor healing, Increased susceptibility to trauma.

- Increase in unwanted facial hair.

- Decrease in scalp hair.

- Decrease in skin strength.

- Increase in laxity, wrinkles, pigmentary changes, xerosis, slackness, cherry angiomas, seborrhic keratosis, telangiectasia, purpura, ecchymosis. 


\section{REVIEW ARTICLE}

\section{HAIR CHANGES:}

Hirsutism: abnormal hair growth on face. The problem in these women is that the hair is more sensitive than normal to small amounts of hormone. The hair grows more quickly and thicker in response to it. The increased hair growth is usually first noted in late teenage years and tends to gradually get more severe as the woman gets older. The main conditions associated with excessive androgens are polycystic ovaries and less often, congenital adrenal hyperplasia.

Greying, thinning, dryness and brittleness of Hair: Increases with age.

There can be two type of hair loss:

Androgenetic alopecia Female pattern Alopecia: most common, caused by male hormones. Hair loss that occurs due to an underlying susceptibility of hair follicles to androgenic miniaturization. There is hair recession at the temples, vertex, and top of the scalp.

Telogen Shedding: loss of hair over a short period of time due to dramatic hormonal changes.
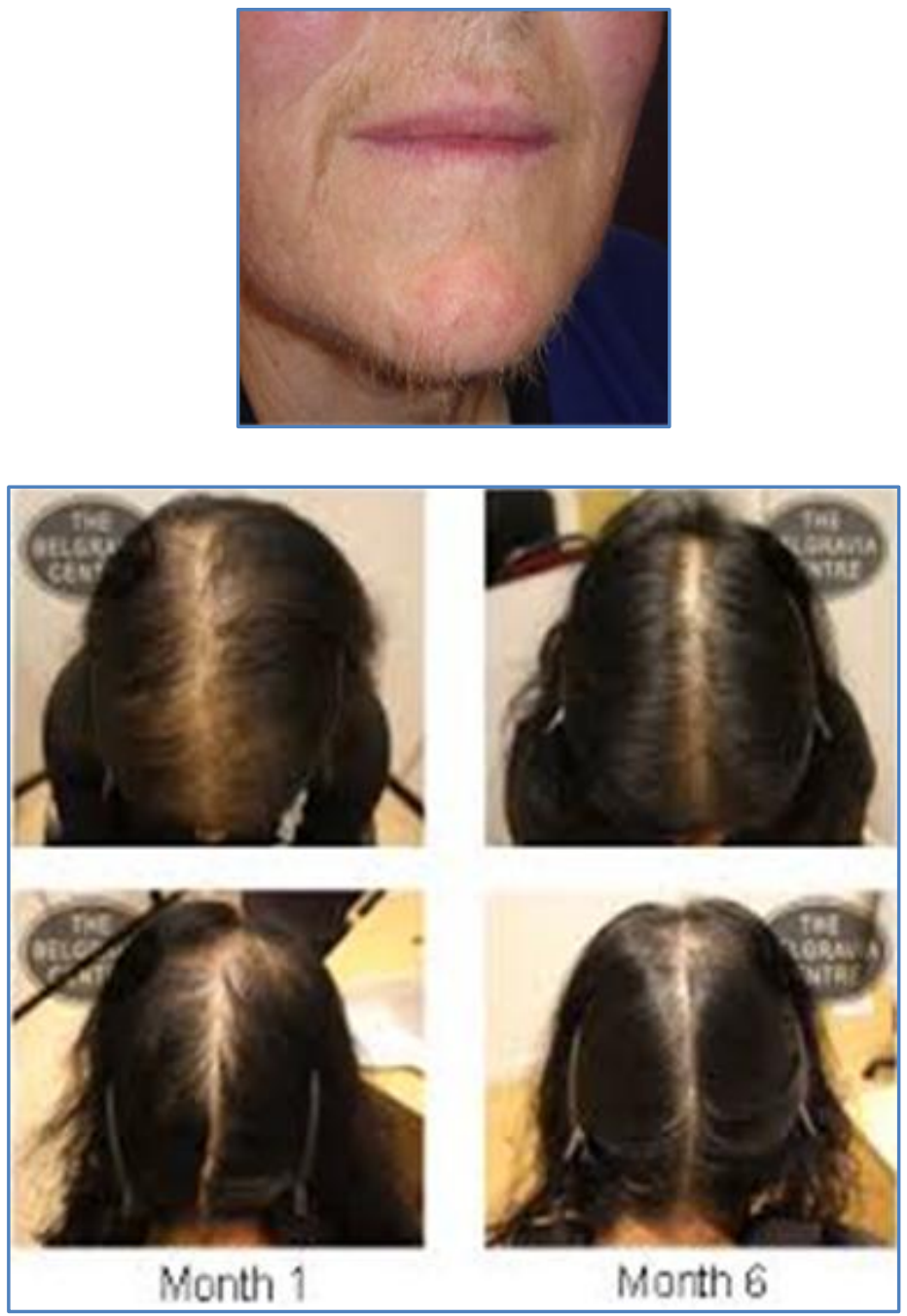

Fig. 1: Showing hirsutism on face and female androgenic alopecia 
Care and management: Everyone realizes that skin shows increasing signs of ageing as the years pass although this seems to accelerate in our late 40's it happens to both women and to men.

1. Collagen support: Look for ingredients that encourage an increase in collagen production and, ideally, the glycosaminoglycans (GAGs) that help fill out the skin. This is done with the help of daily applications of Retin A products.

2. AHA's: Acids increase the thickness of the epidermis and decrease the thickness of the dead superficial cells, especially lactic acid which is the main ingredient in the facial washes to improve GAG content and help normalize the tone of the skin.

3. Sun Protection: Because the sun's UV rays do substantial damage, you should regularly use sun protection. Don't be afraid of getting a modest amount of sun on your body regularly as it is crucial for helping provide your body with active vitamin D.

\section{Sun screens which can be either:}

Chemical (UVA, UVB) or physical type.

Systemic sunscreen like b-carotene and hydroxychloroquine.

Oral Anti-oxidants reduces UV induced skin damage.

\section{Facts about sunscreens:}

Most facial foundation contains titanium dioxide.

UPF (UV protection factor) measurement guidelines for clothing. Fabrics with tighter weaves, darker colours, synthetic fibres and loose fit provide greatest protection.

Polyester cloth has a SPF of 2, and cotton has SPF of 15.

About $90 \%$ of summer clothes usually cotton have a UPF higher than 10 .

Washing clothes appears to strengthen the UPF.

Wearing a broad brimmed hat can provide an SPF of about 5.

Goggles and umbrellas can add to the protection.

Glass windows can be augmented against UVA by using lumar UV shield (blocks 99.9\%) of UVA.

Hair care products with sunscreens have no validity.

Wet skin and hydration increase the absorption of UV light.

\section{ANTI-OXIDANT PROTECTION:}

Much of the deterioration of the skin occurs through oxidation.

The skin normally has antioxidants present to help counter this effect. Providing additional antioxidants through topical application can help further protect the skin. No single antioxidant is a 'miracle'; use products that combine complementary antioxidants for the best effect.

Eg; carotenoids, flavonoids, tocopherol, polyphenols, vitamin c.

Lycopene primary carotenoid.

5. MOISTURIZATION: A significant skin function is to keep water in - in the skin and in the body. But, aging skin gradually loses its ability to do so, resulting in dry skin, but also in greater loss of 


\section{REVIEW ARTICLE}

water through the skin. Use of a body lotion that mimics and replaces as much as possible the normal skin oils can help. Eg: ceramides, squalene, vitaminA, glycerin, liquid paraffin, Aloe Vera.

\section{Cosmeceuticals:}

These are cosmetic products that have a medical or drug like benefit.

They contain biological active ingredients.

Combines two words cosmetic plus pharmaceuticals.

\section{Commonly used cosmeceuticals for skin:}

\begin{tabular}{|c|c|}
\hline Retinoids & $\begin{array}{l}\text { Retinol } \\
\text { Retinal } \\
\text { Retinoic acid }\end{array}$ \\
\hline Alpha hydroxy acids & $\begin{array}{l}\text { Glycolic acid } \\
\text { Lactic acid } \\
\text { Tartaric acid } \\
\text { Citric acid }\end{array}$ \\
\hline Beta hydroxy acids & $\begin{array}{l}\text { Salicylic acid } \\
\text { Beta lipohydroxy acid } \\
\text { Tropic acid }\end{array}$ \\
\hline Polyhydroxy acids & $\begin{array}{l}\text { Gluconic acid } \\
\text { Lactobionic acid } \\
\text { galactose }\end{array}$ \\
\hline Antioxidants & $\begin{array}{l}\text { Vitamin A, E, C, B } \\
\text { Lipoic acid } \\
\text { Coenzyme q10 } \\
\text { Niacinamide } \\
\text { Polyphenoles } \\
\text { dimethylaminoethanol }\end{array}$ \\
\hline Skin lightening agents & Phenolic, nonphenolic combinations \\
\hline
\end{tabular}

Cuticle damage results in structural changes to hair shaft leading to weathering. Other factors include UV exposure, excessive wetting, repeated harsh chemical procedures, and repeated brushing and combing. Using appropriate shampoos, conditioners according to hair type helps in repairing the damage.

\section{SHAMPOOS AND CONDITIONER:}

- AMPHOPHILIC: are mildest and have good conditioning effect do not irritate eyes

- Major component of baby shampoo

\section{CONDITIONERS:}

- They have negative charge and adhere to positively charged cuticle and coat the hair adding to shine of hair. 


\section{REVIEW ARTICLE}

- Protein based conditioners get attached to inner hair shaft at cuticular breaks and help in repairing split ends.

- Hair serum contains dimethicone which coats for hair and acts like a film making the hair tangle free and manageable.

\section{Treatment for skin rejuvenation':}

Noninvasive photo rejuvenation method:

- This stimulates collagen synthesis.

- Indicated in fine to moderate wrinkles, periorbital tissue lightening.

\section{Chemical peels:}

- Stimulates epidermal exfoliation, epidermal and dermal rejuvenation, decrease pigmentation

- Indicated in fine wrinkles, melasma, freckles,

- lentigines

- Superficial scars

\section{Microdermabrasion:}

- Stimulates mild exfoliation, epidermal regeneration and collagen formation

- Indicated in fine and superficial scars

\section{Botulinum toxin:}

- Inhibits neuromuscular transmission and weakens the injected muscle

- Indicated in forehead horizontal lines, glabellar, frown lines, crow's feet, marionette lines

\section{Fillers:}

- Fill the wrinkles

- Indicated for nasolabial folds, deep forehead lines, deep perioral wrinkles, lip augmentation

- Hyaluronic acid fillers commonly used

\section{Thread lifts:}

- Pulls up and tightens the face

- Sagging cheeks, brow lift chin lift

\section{Fractional photothermolysis:}

- Stimulates collagen synthesis, fine wrinkles, dyschromia. 


\section{REVIEW ARTICLE}

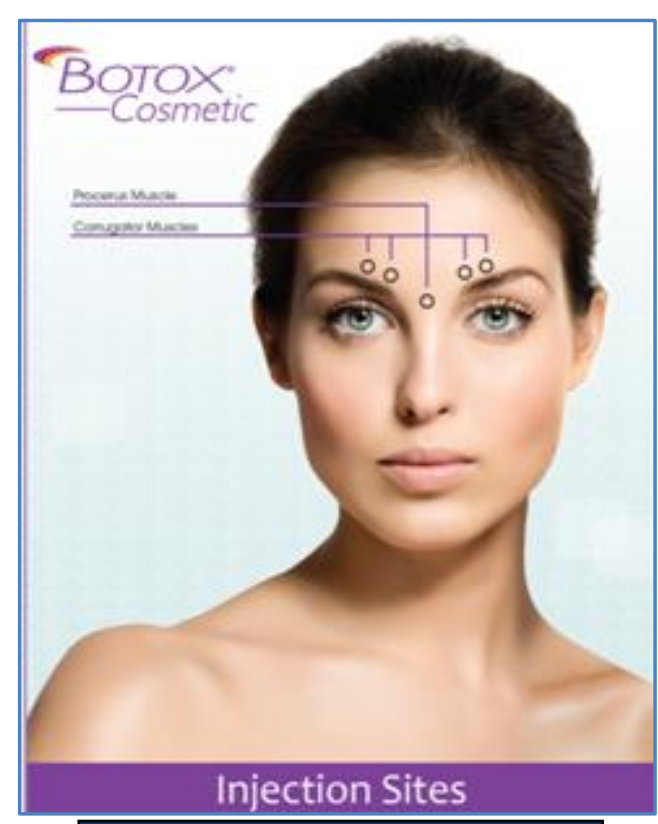

Fig. 2: Botox Injection Site
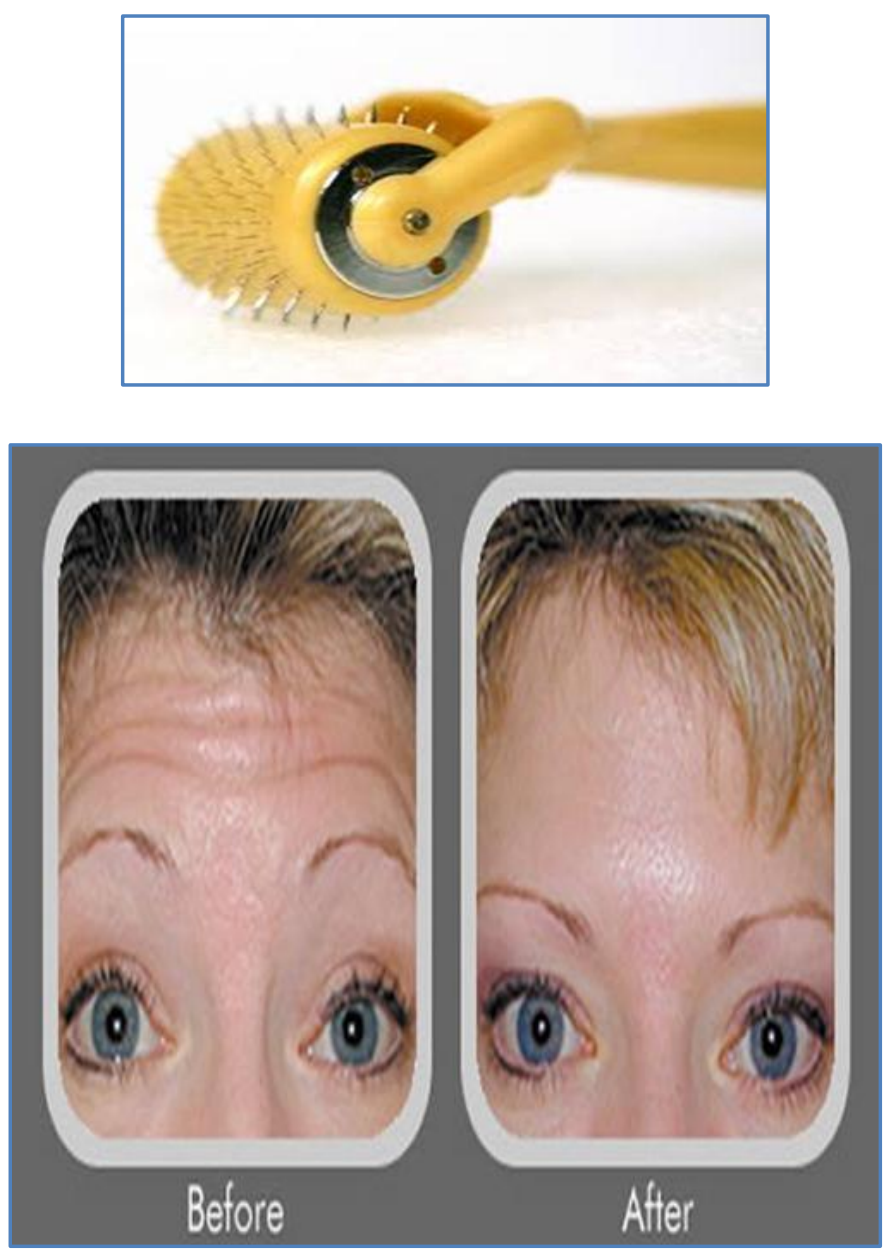

BEFORE AND AFTER EFFECTS OF BOTOX 
FOODS FOR GLOWING SKIN AND HAIR: Carotenoids which exerts photoprotective effects as Antioxidants which include carotenoids, flavonoids, vitamin c, tocopherols polyphenols.

Lycopene is the primary carotenoid which is found in: Tomatoes, apricots, papaya, pink grapefruit,

FOODS WITH SIGNIFICANT POLYPHENOL LEVELS: 10,11

\begin{tabular}{|c|c|c|}
\hline Vegetables & Fruits & Miscellaneous \\
\hline $\begin{array}{l}\text { Broccoli, } \\
\text { cabbage, } \\
\text { eggplant, lettuce, olives, } \\
\text { onions, } \\
\text { soybeans, } \\
\text { spinach }\end{array}$ & $\begin{array}{l}\text { Apples, } \\
\text { apricots, } \\
\text { berries, cherries, citrus fruits, } \\
\text { grapes, } \\
\text { peaches, } \\
\text { plums }\end{array}$ & $\begin{array}{l}\text { Cocoa, } \\
\text { coffee beans, } \\
\text { flaxseeds, grains, nuts, } \\
\text { red wine, tea }\end{array}$ \\
\hline
\end{tabular}

\section{FOODS WHICH IMPROVE DRY SKIN 12,13}

- Avocados, canola oil, evening primrose oil, fish (salmon, tuna).

- Flaxseed oil, nuts, olives, olive oil, peanuts, soy, sunflower, walnuts.

Food to consume and avoid to help keep wrinkles at bay: ${ }^{14}$

\begin{tabular}{|c|c|}
\hline Eat & Avoid \\
\hline Asparagus, celery, eggplant, & Butter, margarine, \\
garlic, legumes, leeks/onions, & milk and milk products, \\
monounsaturated fat, olive oil, spinach & red meat, sugar products \\
\hline
\end{tabular}

FOOD WITH OMEGA-3 FATTY ACIDS: 15,16

- Canola oil, fish (tuna, lake trout, salmon), flaxseeds, hempseed, omega -3 eggs, seaweed, walnuts

CONCLUSION: Alterations to one's lifestyle to ensure long term improvements. We cannot change the intrinsic factors but can alter the environmental and photo induced changes. STRESS is one of the most important factors in aging which can only be worked upon by an individual. Things like exercise, yoga are known stress relievers.

\section{REVIEW OF LITERATURE:}

1. Wespes E, Schulman CC. Male andropause: myth, reality and treatment. Int J Impot Res.2002; 14:s93-8.

2. Philips TJ, Demircay Z, Sahu M. Hormonal effects on skin ageing. Clin Geriatr Med.2001; 17:66172.

3. Arlt W, Hewison M. Hormones and immune function; implications of ageing. Ageing cell.2004; 3:209-16.

4. Gilchrist BA, Krutmann J. Skin ageing. Heidelberg; springer; 2006; 198.

5. Ferguson J, Dover J.S. Photodermatolgy, London: Manson publishing; 2006; 160. 


\section{REVIEW ARTICLE}

6. Boyd AS, StaskoT, King LE, et al. Cigarette smoking-associated elastotic changes in the skin. J AM Acad Dermatol. 1999; 41:23-6.

7. Smith JB, Fenske NA. Cutaneous manifestations and consequence of smoking .J Am Acad Dermatol. 1996; 34: 717-32.

8. Baumann L. Cosmetic dermatology. New York; Mc Graw-hill; 2002; 226.

9. Khunger N. Ageing skin. In; Khunger N, Sachdev M (Eds).Practical Manual of cosmetic Dermatology and surgery, 1 st edition. New Delhi; Mehta publishers; 2010; 177-92.

10. Svobodva A, Psotova J, Walterova D. Natural phenolics in the prevention of UV induced skin damage- A review. Biomed Papers, 2003; 147: 137.

11. Scalbert A, Williamson G. Dietary intake and bioavailability of polyphenols. J Nutr.2000; 130:2073S.

12. Callaway J, Schwab U, HarvimaI et al. Efficacy of dietary hempseed oil in patients with atopic dermatitis. J Dermatolog Treat 2005; 16:87.

13. Davis BC, Kris-Etherton PM. Achieving optimal essential fatty acid status in vegetarians: current knowledge and practical implications. Am J Clin Nutr 2003; 78: 640S.

14. Purba M, Kouris-Blazos A, Wattanapenpaiboon $N$ et al. Skin wrinkling: can food make a difference? J Am Coll Nutr.2001; 20; 71.

15. Boelsma E, Hendriks HF, Roza L. Nutritional skin care: health effects of micronutrition and fatty acids. Am J Clin Nutr.2007; 73; 853.

16. Bourre J M. Dietary omega -3 fatty acids for women. Biomed Pharmacother. 2007; 61: 105.

\section{AUTHORS:}

1. Manisha Nijhawan

2. Shifa Yadav

3. Puneet Aggarwal

4. Dinesh Mathur

\section{PARTICULARS OF CONTRIBUTORS:}

1. Associate Professor, Department of Dermatology, Venereology and Leprosy, Mahatma Gandhi Hospital, Sitapura, Jaipur.

2. Resident, Department of Dermatology, Venereology and Leprosy, Mahatma Gandhi Hospital, Sitapura, Jaipur.

3. Resident, Department of Dermatology, Venereology and Leprosy, Mahatma Gandhi Hospital, Sitapura, Jaipur.
4. Head of Department, Department of Dermatology Venereology and Leprosy, Mahatma Gandhi Hospital, Sitapura, Jaipur.

\section{NAME ADDRESS EMAIL ID OF THE} CORRESPONDING AUTHOR:

Dr. Manisha Nijhawan, \#112, Panchsheel Enclave,

JLN Road, Jaipur - 302015,

Rajasthan, India.

E-mail: m.nijhawan12@gmail.com

Date of Submission: 27/01/2014. Date of Peer Review: 28/01/2014.

Date of Acceptance: 27/03/2014.

Date of Publishing: 14/04/2014. 